\title{
ХИМИКО-ГЕНЕТИЧЕСКАЯ ТИПИЗАЦИЯ ПЕРВИЧНЫХ СОЛЯНЫХ ПОРОД ВЕРХНЕКАМСКОГО МЕСТОРОЖДЕНИЯ
}

\author{
И.И. Чайковский \\ Горный институт УрО РАН, г.Пермь
}

\begin{abstract}
Аннотация: Обработка 416 химических анализов первичных соляных пород показала, что основными компонентами, слагающими толщу Верхнекамского месторождения, являются хлориды натрия, калия и магния (галит, сильвин и карналлит) и нерастворимый остаток, представленный главным образом глинистыми минералами. Отмечено, что пласты, сложенные калийными и калийно-магниевыми солями, не являются мономинеральными и содержат постоянную примесь галита, обусловленную строением годового слоя (снизу вверх) - перистый галит, сильвин (или карналлит), зернистый галит. Максимальное содержание карналлита в пластах достигает 90, а сильвина 53 мас.\%. Установлено, что вариации состава первичных соляных пород связаны с проявлением двух основных трендов: опреснением водами суши (ряд галитит - глина рассолонасыщенная) и эвапоритизацией (галитит - сильвинит или карналлитит). Предполагается и незначительное влияние контаминации эоловым материалом во время отложения калийно-магниевых солей. Показано, что одно крупное опреснение с привносом терригенного материала с суши произошло во время накопления подстилающей каменной соли (глинистый пласт МГ), среднее (или средние) - во время сильвинитовой садки и более мелкие при осаждении карналлита. Несмотря на локальные события (опреснение и поступление эолового материала), общая эволюция хемогенной седиментации в Соликамском палеобассейне на регрессивной стадии проявилась в смене галитовой садки сильвин-галитовой и галит-карналлитовой. Последующее погружение бассейна и интервенция морских вод сделали невозможным отложение бишофита, место которого занял галит.
\end{abstract}

Ключевые слова: Верхнекамское месторождение солей, литохимия, эвапоритизация, опреснение.

Галогенная толща Верхнекамского месторождения сложена (снизу-вверх) подстилающей каменной солью (ПдКС), сильвинитовой (С3) и карналлититовой (КЗ) зонами, покровной каменной солью (ПКС). Сильвинитовые и карналлититовые пласты в соответствующих зонах переслаиваются с соляными (т.н. межпластовые галититы). Наблюдаемая последовательность отличается от ряда Вант-Гоффа-Курнакова-Валяшко только отсутствием эпсомитовой (перед сильвиновой) и бишофитовой (после карналлитовой) зон [2], что объясняется обессульфаченностью (метаморфизмом) вод и незавершенностью эвапоритового процесса. В целом месторождение сложено соляными породами относительно простого состава, что позволяет использовать его в качестве эталона (литотипа), для химической типизации пород.

В связи с необходимостью классификации соляных пород Я.Я. Яржемским и др. [1] была предложена типизация, основанная на содержании сильвина, количество которого определялось в петрографических шлифах в объемных \%. Породы сложенные галитом и сильвином по мере роста содержания последнего слагают следующий ряд: галит с примесью сильвина (0-5), галитит сильвинсодержащий или бедный (5-15), сильвинит (нормальный) (15-50), сильвинит богатый (более 50 \%). Породы сложенные галитом и карналлитом по мере роста содержания последнего слагают следующий ряд: галитит с примесью карналлита (0-5), галитит карналлитсодержащий (5-15), галит-карналлитовая порода (15-50), карналлитит (более 50\%).

Однако карналлитит- или сильвинитсодержащие пласты сложены несколькими десятками (до сотни и более) годовых слоев, состоящих в свою очередь из слоев скелетно-перистого галитита, сильвинита (или карналлитита) и зернистого галитита. Скелетно-перистая соль может подстилаться тонким слойком глинистого материала (иногда с желваками ангидрита) или содержать эти нерастворимые компоненты в виде рассеянной вкрапленности. В практике химического опробования соляных месторождений пробы отбирают по интервалам разреза содержащим (или не содержащим) сильвин, 
карналлит, бишофит или другой полезный минерал (полигалит, каинит и др.). Таким образом, литологическая типизация по шлифам не отражает реального соотношения породообразующих минералов в пластах.

Для устранения этого противоречия и выявления основных тенденций изменения химического состава было использовано 416 химических анализов, выполненных в аккредитованной лаборатории ООО «Персил», г. Березники. Они отобраны в южной, наиболее глубокой части месторождения наименее подверженной эпигенетическим изменениям, на участке, характеризующемся отсутствием вторичных галититов и пестрых сильвинитов, из скважин, расположенных в пределах одного небольшого разведочного участка, что позволило уменьшить вариации состава в связи с фациальными изменениями. Опробование проведено по 69 интервалам разреза длиной от 20 см до 7 м, отвечающим однородным литологическим разностям от верхней части подстилающей каменной соли, до нижней части покровной каменной соли.

Результаты химического анализа выражались в ионной $\left(\mathrm{K}, \mathrm{Na}, \mathrm{Ca}, \mathrm{Mg}, \mathrm{HCO}_{3}, \mathrm{Cl}\right.$, $\mathrm{SO}_{4}, \mathrm{Br}, \mathrm{H}_{2} \mathrm{O}$ крист. $\mathrm{H}_{2} \mathrm{O}$ гигр. Н.О. (водн.)) и солевой (KCl, $\mathrm{NaCl}, \mathrm{MgCl}_{2}, \mathrm{CaCl}_{2}, \mathrm{CaSO}_{4}$ ) форме. Содержания $\mathrm{CaCl}_{2}$ не превышают 0,6 , а $\mathrm{Br}$ и $\mathrm{MgSO}_{4}-0,2$ мас.\%, что позволяет опустить их из классификационных признаков. Вариации значимых компонентов показаны в таблице.

Таблица

Вариации химического состава соляных толщ Верхнекамского месторождения, мас.\%

\begin{tabular}{|c|c|c|c|c|c|c|}
\hline Толщи & $\mathrm{NaCl}$ & $\mathrm{KCl}$ & $\mathrm{MgCl}_{2}$ & $\begin{array}{c}\mathrm{H}_{2} \mathrm{O} \\
\text { крист. }\end{array}$ & $\begin{array}{c}\mathrm{H} . \mathrm{O} . \\
\text { (водн.) }\end{array}$ & $\mathrm{CaSO}_{4}$ \\
\hline ПКС & $91,8-95,5$ & $0,2-0,21$ & $0,2-0,6$ & $0,3-0,7$ & $1,1-2,4$ & $1,3-3,6$ \\
\hline $\mathrm{K} 3$ & $6,6-96,4$ & $0,1-27,3$ & $0,24-31,1$ & $0,3-37,7$ & $0,5-21,0$ & $0,1-5,2$ \\
\hline $\mathrm{C} 3$ & $45,4-95,7$ & $0,2-51,1$ & $0,03-2,18$ & $0,03-2,5$ & $0,6-35,0$ & $0,3-5,0$ \\
\hline ПдКС & $90,7-97,6$ & $0,02-0,4$ & $0,04-0,5$ & $0,04-0,9$ & $0,5-4,8$ & $1,1-3,4$ \\
\hline
\end{tabular}

В целом по результатам химического анализа видно, что основными минералами, слагающими соляную залежь Верхнекамского месторождения, являются три хлоридных минерала (галит, сильвин и карналлит) и нерастворимый остаток. Содержание сульфата кальция, вероятно несколько выше, поскольку предполагается, что не все количество перешло в водный раствор при подготовке химического анализа, но его содержание по разрезу не сильно различается и не превышает 10 мас.\%. Нерастворимый в воде остаток (Н.О. водн.) представлен главным образом глинистыми минералами, в меньшей мере - сульфатами и карбонатами. Содержание кристаллизационной воды находится в прямой связи с содержанием хлорида магния (и калия) и связано в составе карналлита. Таким образом, для типизации пород по химическому составу целесообразно использовать содержания следующих значимых (литогенных) компонентов ( $\mathrm{NaCl}, \mathrm{KCl}, \mathrm{MgCl}_{2}$, H.O.)

Построение и анализ диаграммы KCl-NaCl- $\mathrm{MgCl}_{2}$ позволяет показать, что пласты, сложенные сильвинитами и карналлититами, характеризуются широкими вариациями состава, обусловленным тем, что слагающие их годовые слои характеризуются различным соотношением мощности галита и сильвина (или карналлита). Максимальное содержание сильвина достигает 53, а карналлита 90 мас.\%, что связано с существенно большей мощностью слоев карналлита, по сравнению с сильвиновыми. И сильвиниты, и карналлититы характеризуются бимодальным составом, что позволяет их разделить на бедные и богатые. 


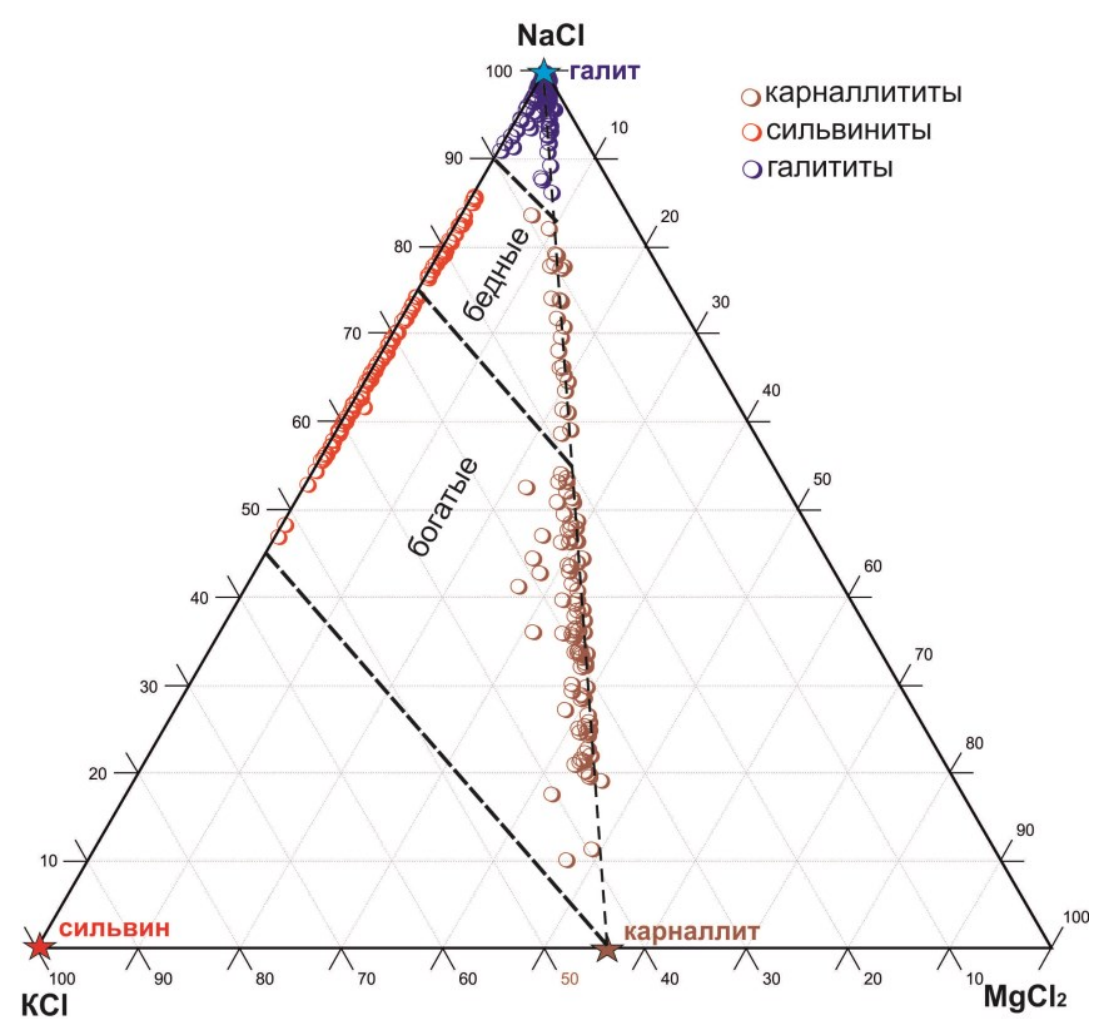

Рис. 1. Соотношение хлоридов калия, натрия и магния (мас. \%) в первичных соляных породах Верхнекамского месторождения. Звездочками показаны теоретические составы минералов

Использование диаграммы NaCl-H.O.- $\mathrm{KCl}$ для сильвинитовой зоны (рис 2a), покровной и подстилающей каменной соли, а также диаграммы NaCl-H.O.$\left(\mathrm{KCl}+\mathrm{MgCl}_{2}+\mathrm{H}_{2} \mathrm{O \kappa р}\right.$.) для карналлититовой зоны (рис. 3а) позволяет отметить следующее. Наиболее чистыми в отношении посторонних примесей являются галититы покровной и подстилающей каменной соли. Содержание галопелитового материала не превышает в них 3 и 5 мас.\% соответственно. Исключением является пласт, существенно глинистого состава, который называется маркирующим горизонтом (пласт МГ). Составы галититов сильвинитовой и карналлитовой зон характеризуются более существенной примесью глинистого материала: до 35 и 23 мас. \%, соответственно. С ростом содержания нерастворимого остатка в этих породах возрастает и содержание хлорида калия (в сильвинитовой зоне) и хлоридов калия и магния (в карналлитовой), что может отражать наличие нормативного сильвина и карналлита в рассоле сорбированном глинистой фракцией. Для составов сильвинитов и карналлититов, в целом, характерно уменьшение примеси нерастворимого остатка с уменьшением содержания галита, хотя отмечаются незначительное количество проб выбивающиеся из этой закономерности.

Таким образом, составы соляных пород Верхнекамского месторождения локализованы вдоль линий галитит - глина рассолонасыщенная (галопелит) и галитит сильвинит (или галитит-карналлитит), которые могут быть обусловлены привносом терригенного материала пресными водами суши и эвапоритизацией, соответственно. То есть общая последовательность отложения солей от натриевых к калиевым, а затем калийно-магниевым осложнялась не только сезонной цикличностью, но и более крупной, связанной с эпизодическим, но более значительным притоком в бассейн водноглинистого материала. Составы сильвинитов и карналлититов с повышенным содержанием нерастворимого остатка при низком содержании галита, могут быть связаны с привносом эолового материала в засушливые периоды. 


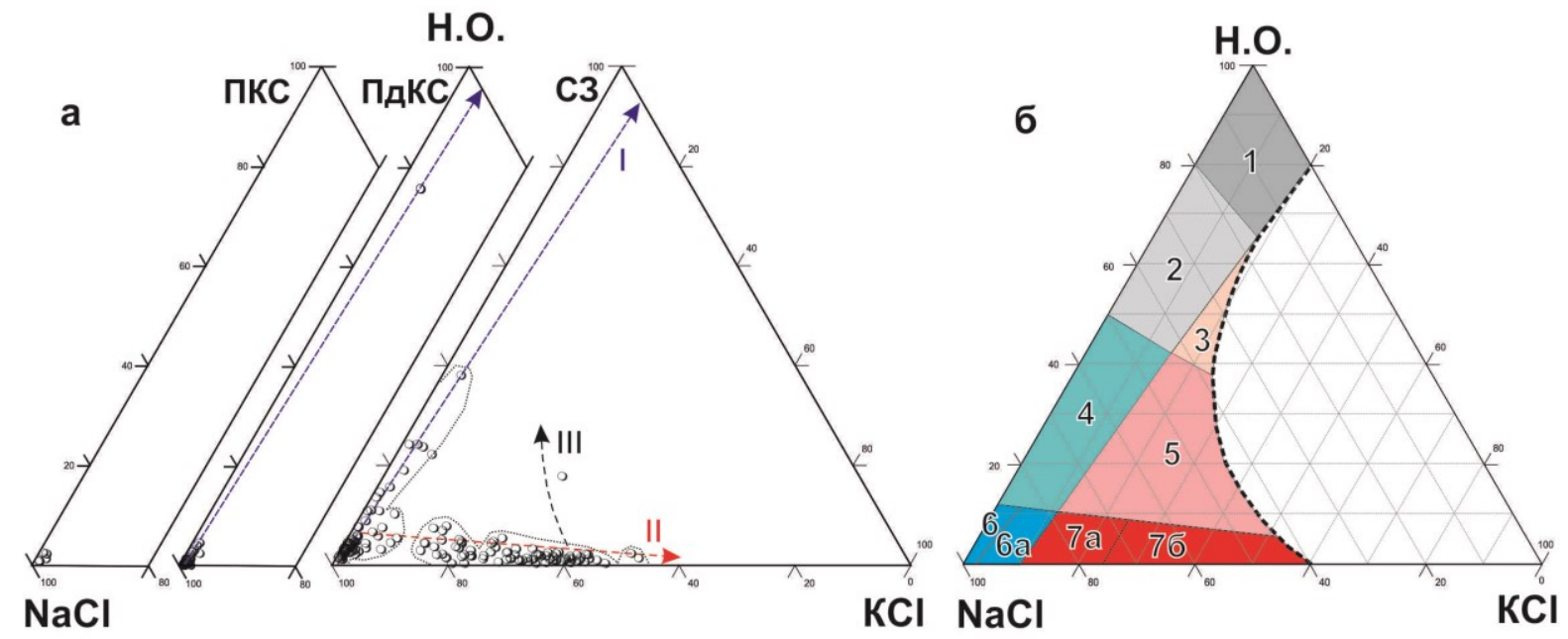

Рис. 2. Соотношение $\mathrm{NaCl}-\mathrm{H} . \mathrm{O} .-\mathrm{KCl}$ (а) и предлагаемая литологическая типизация (б) пород, слагающих толщи Верхнекамского месторождения: ПКС - покровная каменная соль, ПдКС - подстилающая каменная соль, С3 - сильвинитовая зона. Поля пород: 1 - глина рассолонасыщенная (галопелит); 2 - глина галитовая; 3 - глина сильвин-галитовая; 4 - галитит глинистый; 5 - сильвинит глинистый; 6 - галитит (в том числе сильвинсодержащий, 6а); 7 - сильвинит (а - бедный, б - богатый). Стрелками показаны основные тренды опреснения (I, галитит - галопелит), эвапоритизации (II, галитит - сильвинит) и контаминации эоловым материалом (III, сильвинит - галопелит)
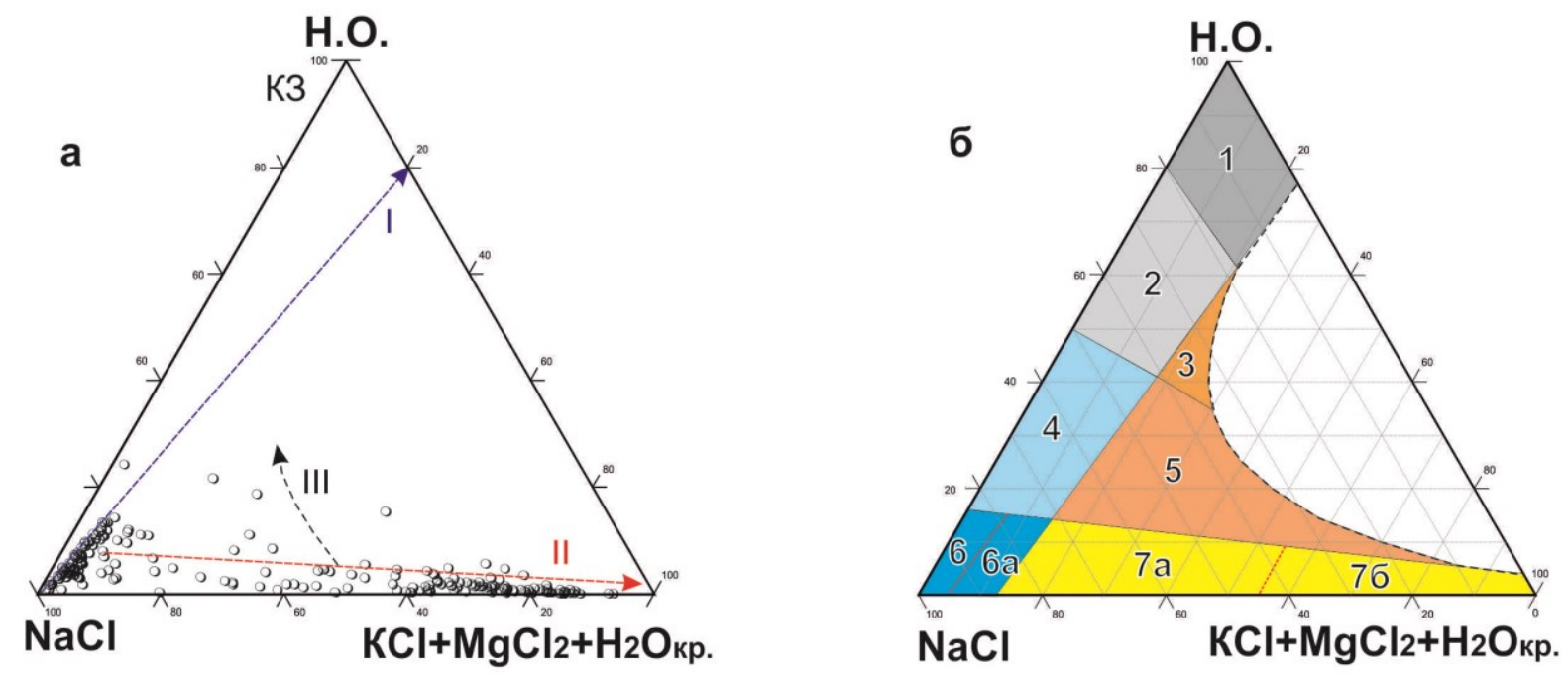

Рис. 3. Соотношение $\mathrm{NaCl}-\mathrm{H} . \mathrm{O} .-\left(\mathrm{KCl}+\mathrm{MgCl}_{2}+\mathrm{H}_{2}\right.$ Окр.) (а) и предлагаемая литологическая типизация (б) пород слагающих карналлититовую зону (К3) Верхнекамского месторождения: 1 - глина рассолонасыщенная (галопелит); 2 - глина галитовая; 3 - глина карналлит-галитовая; 4 - галитит глинистый; 5 - карналлитит глинистый; 6 - галитит (в том числе карналлитсодержащий, 6a); 7 - карналлитит (а - бедный, б - богатый). Стрелками показаны основные тренды опреснения (I, галитит - галопелит), эвапоритизации

(II, галитит -карналлитит) и контаминации эоловым материалом (III, карналлитит - галопелит)

Отклонение основных трендов вариации составов от сторон диаграммы и наличие отдельных скоплений (мод) на них позволяет предложить контуры полей пород (рис. $26,36)$, несколько отклоняющиеся от традиционных (формальных) границ $(10,50,90$ \%) проводимых между литологическими разностями, что обусловлено реальными взаимоотношениями компонентов. Кроме того, в пределах некоторых полей проведены дополнительные границы позволяющие разделить галитит от галитита сильвинсодержащего, а в сильвинит и карналлитит - на бедную и богатую разность.

Приведенные в работе [3] графические материалы дают основание полагать, что на Старобинском месторождении содержание $\mathrm{KCl}$ достигает более высоких значений, а с 
уменьшением примеси $\mathrm{NaCl}$ количество нерастворимого остатка несколько возрастает, что может говорить о более значимой роли эоловых процессов. Таким образом, границы полей на предложенной типизации для других месторождений могут быть адаптированы с учетом локальной специфики седиментационных процессов.

Исследования выполнены при поддержке гранта РФФИ № 18-05-00046.

\title{
БИБЛИОГРАФИЧЕСКИЙ СПИСОК
}

1. Атлас структур и текстур галогенных пород СССР / науч. ред. Я.Я. Яржемский; ВНИИГ. - Л., Недра, 1974. - $231 \mathrm{c}$.

2. Валяшко М.Г. Геохимические закономерности формирования месторождений калийных солей. - М.: МГУ, 1962. - 397 с.

3. Протопопов А.Л., Петров Е.В. Некоторые особенности постседиментационных преобразований калиеносных пород (на примере Верхнекамского и Старобинского месторождений) // Основные проблемы соленакопления: [сб. ст.]. - Новосибирск, 1981. - С. 59-71.

\section{МЕХАНИКА ГОРНЫХ ПОРОД}

УДК 622.83

DOI:10.7242/echo.2020.1.7

\section{ВЛИЯНИЕ БАРЬЕРНЫХ ЦЕЛИКОВ \\ НА СТЕПЕНЬ НАГРУЖЕНИЯ \\ ЭЛЕМЕНТОВ КАМЕРНОЙ СИСТЕМЫ РАЗРАБОТКИ}

\author{
П.А. Глебова \\ Горный институт УрО РАН, г. Пермь
}

\begin{abstract}
Аннотация: Методами математического моделирования с целью определения влияния барьерных целиков на элементы камерной системы разработки проведен анализ перераспределения вертикальных нагрузок на основе гипотезы действия веса всей налегающей толщи, а также метода фиктивных целиков. Выполнена оценка устойчивости целиков путем определения их степени нагружения.

Ключевые слова: математическое моделирование, горное давление, барьерные целики, междукамерные целики, степень нагружения.
\end{abstract}

Правильный выбор системы разработки рудника является первоочередным фактором, обеспечивающим его защиту от затопления.

При освоении калийных и соленых месторождений одной из наиболее применяемых является камерная система разработки с оставлением междукамерных целиков (МКЦ). В этом случае определение их степени нагружения, как критерия устойчивости, в основном базируется на методике Турнера - Шевякова $[1,2]$, которая нашла широкое практическое применение в инженерной геомеханике. В основе метода лежит предположение, что давление на целики определяется весом столба пород от кровли залежи до земной поверхности и ограниченного осями симметрии камер, прилегающих к целику.

Особенности геологического строения месторождения, таких как большая глубина отработки, или возникновение других сложных проблем приводят к невозможности использования периодической системы междукамерных целиков, в частности за счет существенного увеличения горного давления. В таких случаях отработку целесообразно вести камерной системой разработки с поддержанием вышележащей толщи опорными барьерными разгружающими целиками (БЦ) в сочетании с междукамерными целиками. Характерными примерами могут служить Жезказганское (Казахстан) [3] и Саскачеванское (Канада) [4] месторождения. 